\title{
Safety Assessment for Electrical Motor Drive System Based on SOM Neural Network
}

\author{
Linghui Meng, Peizhen Wang, Zhigang Liu, Ruichang Qiu, Lei Wang, and Chunmei Xu \\ School of Electrical Engineering, Beijing Jiaotong University, Beijing Engineering Research Center of Electric Rail Transportation, \\ Beijing 100044, China \\ Correspondence should be addressed to Linghui Meng; 13810476488@163.com
}

Received 19 December 2015; Accepted 16 February 2016

Academic Editor: Wen Chen

Copyright (C) 2016 Linghui Meng et al. This is an open access article distributed under the Creative Commons Attribution License, which permits unrestricted use, distribution, and reproduction in any medium, provided the original work is properly cited.

\begin{abstract}
With the development of the urban rail train, safety and reliability have become more and more important. In this paper, the fault degree and health degree of the system are put forward based on the analysis of electric motor drive system's control principle. With the self-organizing neural network's advantage of competitive learning and unsupervised clustering, the system's health clustering and safety identification are worked out. With the switch devices' faults data obtained from the dSPACE simulation platform, the health assessment algorithm is verified. And the results show that the algorithm can achieve the system's fault diagnosis and health assessment, which has a point in the health assessment and maintenance for the train.
\end{abstract}

\section{Introduction}

Urban rail train traction drive system is the key subsystem of the train, which is the guarantee for the train's safe and smooth running. However, urban rail train's motor drive system is a multivariable, nonlinear, strong coupling complex system. Its failure frequency and failure mode are intricate, mutual coupling interference, which seriously affected the safety and reliability of the train. However, the present process of fault identification and intervention "backwardness" determines its inevitable failure, which is limited for improving the safety. So the traditional urban rail train motor drive system needs online, real-time, fast health assessment and safety assessment. Safety control measures also should be taken in time to ensure the train's safe running.

Reference [1] introduced the idea of the machine learning and artificial intelligence to fault diagnosis for the motor drive system, which is effective for the intelligent algorithm to solve the complex system's fault diagnosis; [2] used the entropy weight multi-information algorithm to complete a comprehensive health assessment for the high-speed catenary, which plays a positive role in health monitoring and safety early warning for the catenary; $[3,4]$ applied the SOM neural network to the fault diagnosis and health evaluation for the steam turbine and the forest system, respectively, which embodied the SOM network algorithm's unique advantage of fault diagnosis and health evaluation.

References [5-8] used the traditional methods of the physical aging damage mechanism of the system level for the damage assessment and reliability modeling of the train, which achieved the reliability assessment and safety prognosis for the train. References [9-16] used model-based and different intelligent methods such as the neural network and fuzzy logic to research on the diagnosis of power converters. In this paper, based on the above literatures, the control principle of train's motor drive system is analyzed to get the health characteristics factor. Then the dada is obtained from the dSPACE fault simulation platform. At last, the self-organizing feature map network intelligent algorithm is realized by MATLAB2011b to complete the health assessment, and the results showed that the health degree and the safety can be calculated and assessed accurately, which can provide a positive guiding role in safety warning and maintenance for the train.

\section{The Analysis of System Health Parameters}

As can be seen from Figure 1, urban rail train's motor drive system mainly includes the traction inverter and traction motor which is controlled by the space vector modulation 


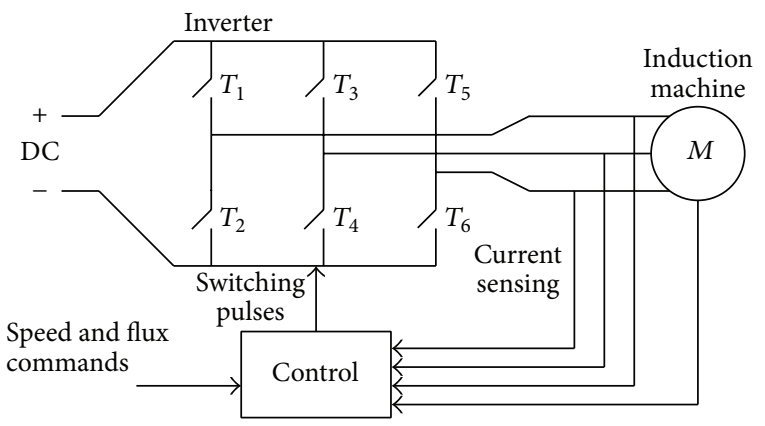

FIgURE 1: AC motor drive system.

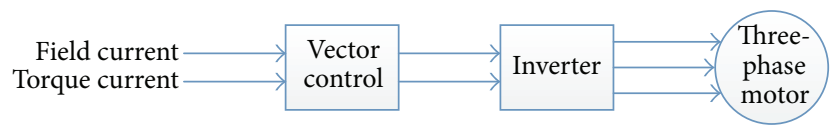

Figure 2: Vector control system.

algorithm. The basic principle of vector control is to measure and control the stator current vector of the induction motor and control field current and torque current of the induction motor, respectively, according to the principle of magnetic field orientation which is described in Figure 2, so as to realize the induction motor torque control.

Traction inverter converts the DC voltage required by the traction system to variable voltage and variable frequency three-phase AC power supply for three-phase induction motor. So the inverter's output voltage and current waveform quality directly affect the performance of motor drive system and also reflect the health status of the motor drive system. In addition, three-phase motor's output torque and speed also directly reflect the traction motor's traction ability, which also indirectly reflects the health status of the motor drive system. So the three-phase output voltage, three-phase output current, output torque, and speed are identified as the health variables to analyze the health characteristics of motor drive system.

\section{Health Characteristic Parameters Extraction}

3.1. Data Preprocessing. Lu Murphey et al. [1] presented a model-based fault diagnostics system which used the threephase voltages and currents as feature signal for detecting and locating multiple classes of faults in an electric drive and achieved good results. Bowen [17] and Diallo et al. [18] researched on the fault diagnosis of inverter's open circuit with the three-phase currents and voltages. Based on the literature above, when the system is in a stable state, the health status of motor drive system can be reflected by three-phase voltage, three-phase current, and torque and speed, which are, respectively, $V_{a n}, V_{b n}, V_{c n}, I_{a}, I_{b}, I_{c}, T_{e}$, and $S$, of which $V_{a n}, V_{b n}$, and $V_{c n}$ represent the root mean square value of three-phase voltage, respectively, $I_{a}, I_{b}$, and $I_{c}$ represent the root mean square value of three-phase current, respectively, and $T$ and $S$ represent the average torque and speed, respectively.
Suppose the number of sampling voltages $V_{\text {in }}(i=$ $a, b, c)$ in time $t$ is $N$, and the samples are $V_{i n}{ }^{1}, V_{\text {in }}{ }^{2} \cdots V_{\text {in }}{ }^{N}$, respectively; then

$$
V_{\text {in }}=\sqrt{\frac{\left(V_{\text {in }}{ }^{1}\right)^{2}+\left(V_{\text {in }}{ }^{2}\right)^{2}+\cdots+\left(V_{\text {in }}{ }^{N}\right)^{2}}{N}} .
$$

The number of sampled currents $I_{i}(i=a, b, c)$ in time $t$ is $M$, and the samples are $I_{i}{ }^{1}, I_{i}{ }^{2} \cdots I_{i}{ }^{M}$, respectively; then

$$
I_{i}=\sqrt{\frac{\left(I_{i}{ }^{1}\right)^{2}+\left(I_{i}^{2}\right)^{2}+\cdots+\left(I_{i}^{M}\right)^{2}}{M}} .
$$

The number of types of sampled torque $T_{e}$ in time $t$ is $P$, and the samples are $T_{e}{ }^{1}, T_{e}{ }^{2} \cdots T_{e}{ }^{P}$, respectively; then

$$
T_{e}=\frac{T_{e}{ }^{1}+T_{e}{ }^{2}+\cdots+T_{e}^{P}}{P} .
$$

The number of sampled speeds $S$ in time $t$ is $Q$, and the samples are $S^{1}, S^{2} \cdots S^{Q}$, respectively; then

$$
S=\frac{S^{1}+S^{2}+\cdots+S^{Q}}{Q} .
$$

3.2. Health Characteristics Factor Calculation. Suppose that the variables' rating standard values of the system in steady state are $V_{a n}, V_{b n}, V_{c n}, I_{a}, I_{b}, I_{c}, T_{e}$, and $S$, respectively, and the values different between the actual state and standard state represent the health status of the system. The greater the deviation is, the worse the system health is. To the contrary, the smaller the deviation is, and the better the system health is. Therefore, the health characteristics factor can be described as

$$
\begin{aligned}
& x_{1}=\left|\frac{V_{a n}-V_{a n}{ }^{*}}{V_{a n}{ }^{*}}\right|, \\
& x_{2}=\left|\frac{V_{b n}-V_{b n}{ }^{*}}{V_{b n}{ }^{*}}\right|, \\
& x_{3}=\left|\frac{V_{c n}-V_{c n}{ }^{*}}{V_{c n}{ }^{*}}\right|, \\
& x_{4}=\left|\frac{I_{a}-I_{a}{ }^{*}}{I_{a}{ }^{*}}\right|, \\
& x_{5}=\left|\frac{I_{b}-I_{b}{ }^{*}}{I_{b}{ }^{*}}\right|, \\
& x_{6}=\left|\frac{I_{c}-I_{c}{ }^{*}}{I_{c}{ }^{*}}\right|, \\
& x_{7}=\left|\frac{T_{e}-T_{e}{ }^{*}}{T_{e}{ }^{*}}\right|, \\
& x_{8}=\left|\frac{S-S^{*}}{S^{*}}\right| .
\end{aligned}
$$




\section{Health Assessment Based on Self-Organizing Feature Map Network}

4.1. The Principle of Self-Organizing Feature Map Network. Self-organizing feature map (SOM) model [19] is a kind of competitive neural network, which introduces the selforganizing characteristics and is the same as competitive neural network by using unsupervised learning style. The difference is that the self-organizing map network can not only learn the distribution of input samples but also identify the topology of the input vector. Classifications are performed by multiple neurons interop with each other. Figure 3 is the network's structure diagram. The self-organizing map network contains two layers which are the input layer and the output layer. the input and output neurons are linked together by weight; at the same time, neighboring neurons are also linked by weight vector. The transfer function of the output neurons is mainly the linear function so the output value is the sum of the linear weighted input value. Suppose that the number of input neurons is $m$, the output neuron is $n$, weight is $w_{i j}$, and the output value of the output neurons $Y_{j}$ will be

$$
Y_{j}=f\left(\sum_{i} x_{i} w_{i j}\right) .
$$

Self-organizing feature map algorithm is a kind of clustering method without teachers, which can map any input mode into one-, two-, or multidimensional discrete graphics in the output layer and still keep its structure unchanged. The learning process can be described as follows: for each of the networks input health characteristics, it just adjusts parts of the weights, which make the weight vectors more close or far from the input vector. And the adjustment process is called the competitive learning. As the continuous learning, the weight vectors in the input space are separated and form a mode which represents the input space, respectively, which realizes the clustering of the health characteristics and health level.

4.2. The Network Learning and Health Assessment. Figure 4 is the flow chart of for the network learning and system health assessment. The healthier the system is, the smaller the deviation value is. Therefore the fault degree of the clustering neurons' output is lower, and the health degree is higher. The following is to explain how the clustering parameters are selected and the training steps of the network, respectively.

4.2.1. The Selection of Clustering Parameters. Parameters here are mainly the number of categories. When we use the selforganizing feature map network to cluster, the structure of the competition layer is set as $3 \times 3$ and the clustering category of the number is 9 . As for meticulous category the system health will be divided into many health levels that do not have much point. While it is not enough detailed, if only it is divided into two categories. As the input vector is 8 dimensions, so the network's input layer contains eight neuron nodes and the competitive layer contains nine neuron nodes. After the training, each input vector belongs to a competitive layer

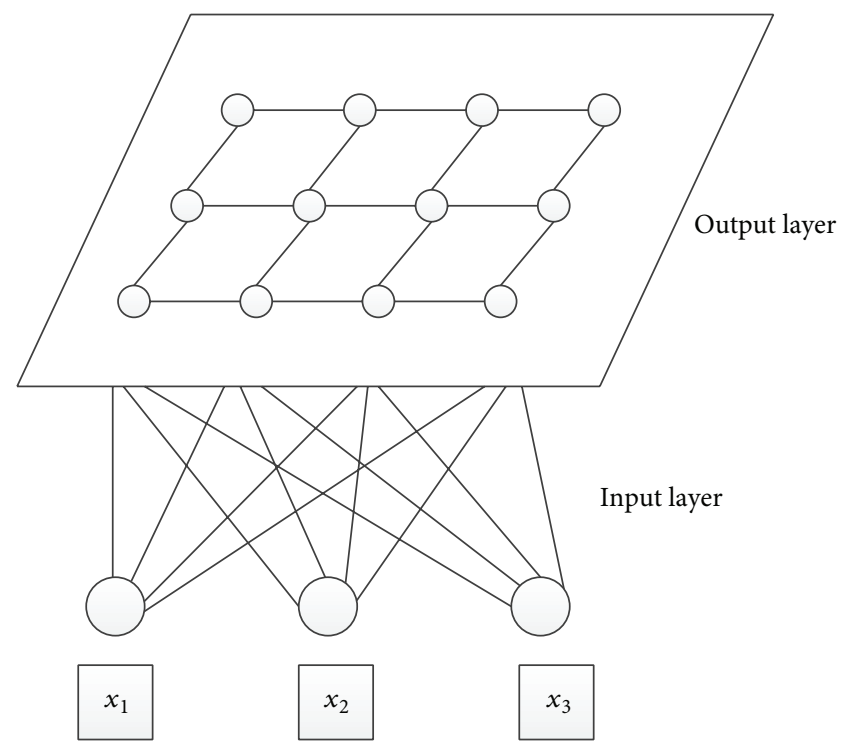

FIGURE 3: SOM neural network.

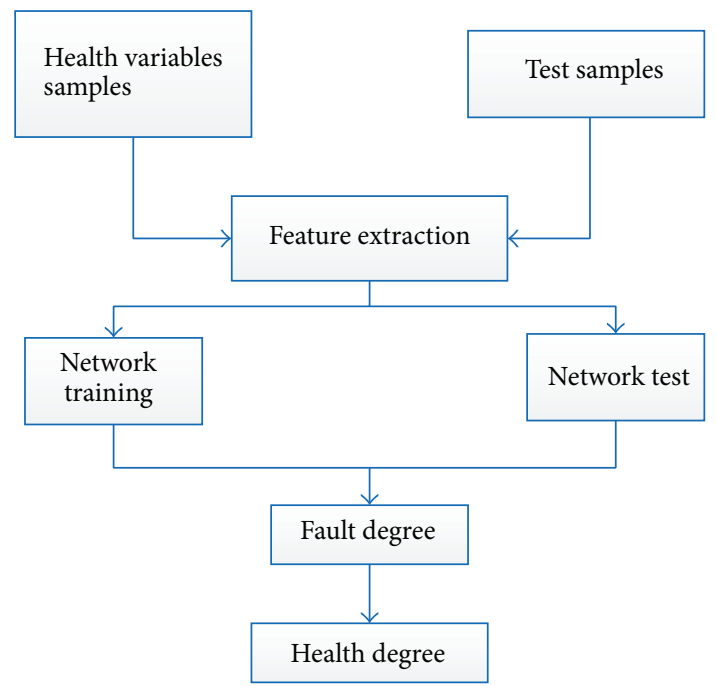

FIgURE 4: The flow chart of network learning and health assessment.

node. And the fault degree $D$ of network's output ranges from 0.1 to 0.9 . 0.1 means the system is in normal or safe state, while 0.9 means that the system has a major failure, and the number between them means that the system is in a state of degradation failure. The higher the fault degree is, the more serious the system failure is. Thus the system health degree $H$ is defined as follows:

$$
H=(1+\varepsilon-D) \times 100 \% .
$$

Among them, $D$ is the system's damage degree which is also the fault degree. $H$ is the system's health degree, and $\varepsilon$ is the correction coefficient of the system health and generally ranges from 0 to 0.1 .

4.2.2. Network Training. SOM network's training steps [19] are as follows. 


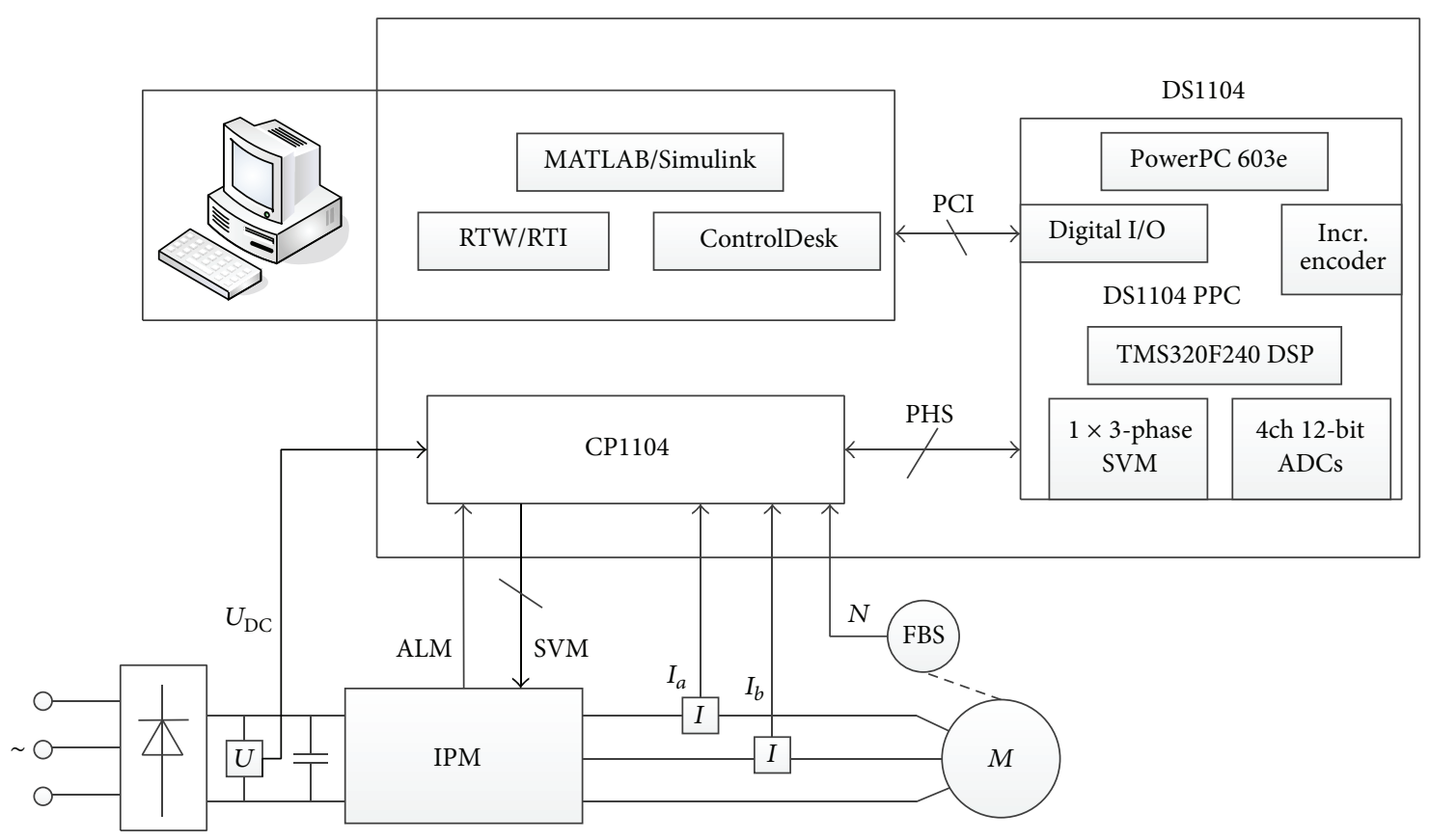

FIGURE 5: System health degradation simulation platform based on dSPACE.

Set the Variable. As the input sample vector is $x=$ $\left[x_{1}, x_{2}, \ldots, x_{8}\right]$, each sample is eight-dimensional vector. $\omega_{i}(k)=\left[\omega_{i 1}(k), \omega_{i 2}(k), \ldots, \omega_{i n}(k)\right]$ is the weight vector between each of input nodes and output neurons.

Initialization. Small random values are used as initialized weights; then the input vector and weights are normalized as follows:

$$
\begin{aligned}
x^{\prime} & =\frac{x}{\|x\|} \\
\omega_{i}^{\prime}(k) & =\frac{\omega_{i}(k)}{\left\|\omega_{i}(k)\right\|} .
\end{aligned}
$$

Network Input. Samples do dot product with the weight vector, and the maximum of the output neurons will win the competition. As the sample and weight vectors have been normalized, so the minimum Euclidean distance can be worked out by calculating the maximum dot product:

$$
D=\|x-\omega\| .
$$

The neurons who get the minimum Euclidean distance will win as the winning neuron.

Update the Weights. For the neurons on the winning neuron topological neighborhood, Kohonen rule is applied to update:

$$
\omega(k+1)=\omega(k)+\eta(x-\omega(k)) .
$$

Different distance functions can be used to determine the neighborhood; the commonly used Euclidean distance (dist) is the Manhattan distance (mandist), and so forth.
Update the learning rate $\eta$ and the topological neighborhood and normalize the learned weights. Learning rates and the neighborhood sizes are adjusted according to the stage of sorting and adjustment.

Determine If Convergence. Determine whether the number of iterations reaches the maximum; if it did not reach the maximum number of iterations, then go to the third step or end the algorithm.

\section{Simulation Experiments and Results Analysis}

5.1. Simulation Model and Test. The motor drive fault simulation experiment is conducted by the dSPACE real-time simulation platform [17]. The platform mainly consists of the computer, dSPACE software system, dSPACE hardware control board DS1104 PPC, dSPACE hardware control panel CP1104, voltage and current sensors, signal detection unit, and an intelligent power module (IPM). The vector control system structure of the induction motor set up by dSPACE real-time simulation platform is shown in Figure 5.

Figure 5 shows the architecture of the real-time dSPACE simulation system. With the dSPACE software control model, the motor vector control model can be quickly converted into code and downloaded to the DS1104 hardware control panel with RTW/RTI. The control panel CP1104 converted the control and protection signal from TMS320F240DSP to a standard IPM signal for controlling the power switch. At the same time, the voltage, current, speed, and other signals are input into the CP1104 hardware control panel via the signal conditioning board and then fed to the input of the model to form a closed loop control. In this paper, a different number of 


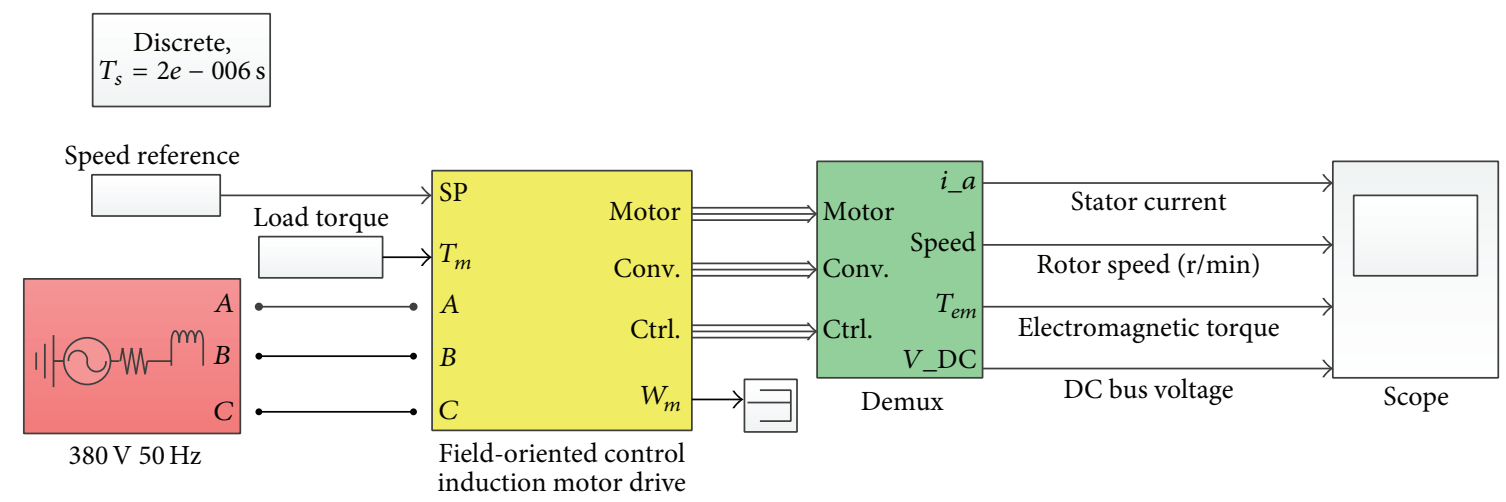

Figure 6: Top-level block diagram of simulation model.

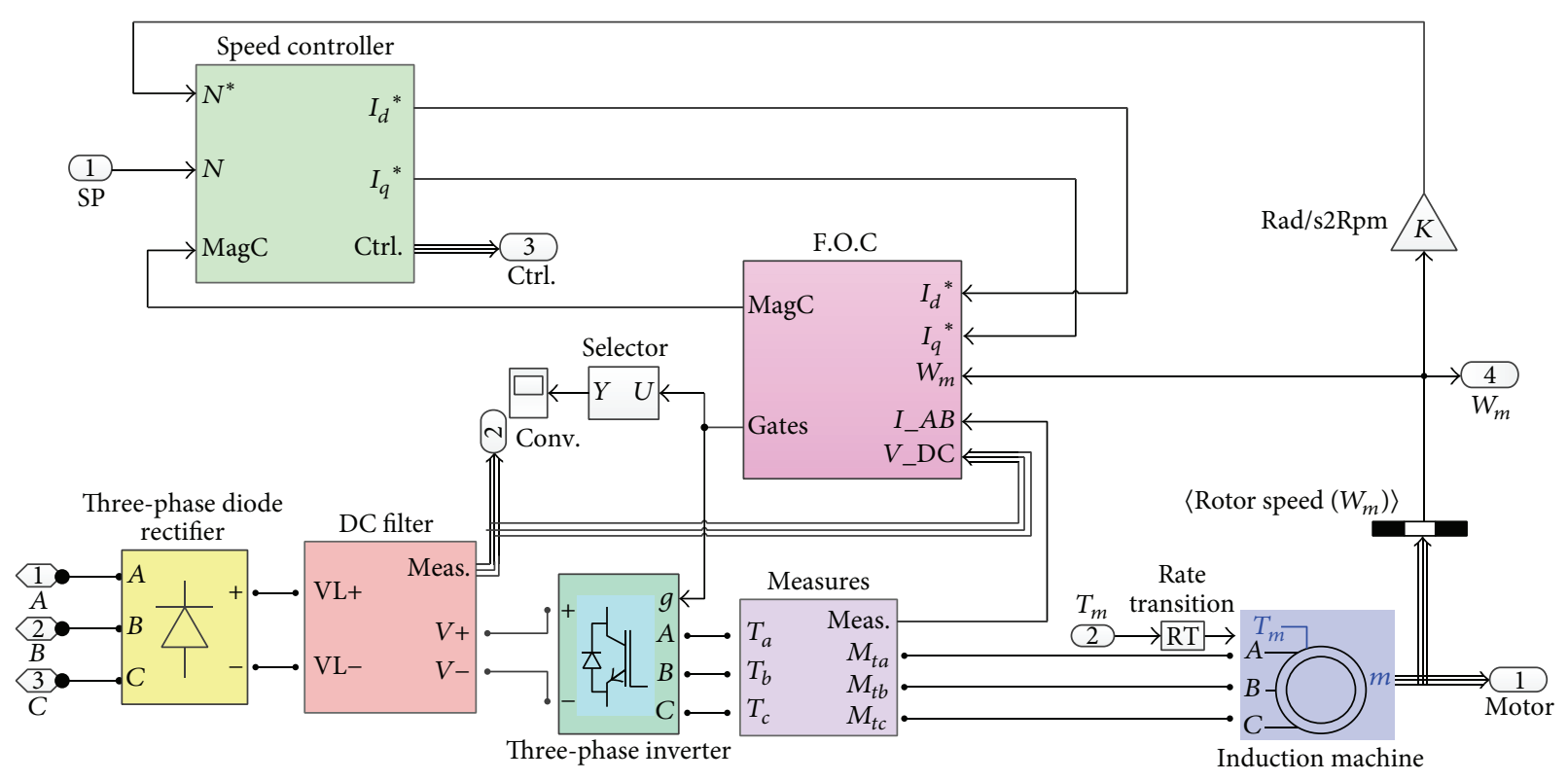

FIGURE 7: Block diagram of RFOC model.

TABLE 1: System health degradation state table.

\begin{tabular}{lc}
\hline Number & Condition \\
\hline 1 & Healthy \\
2 & $T_{1}$ OC \\
3 & $T_{2}$ OC \\
4 & $T_{1}, T_{2}$ OC \\
5 & $T_{1}, T_{3}$ OC \\
6 & $T_{1}, T_{2}, T_{3}$ OC \\
7 & $T_{1}, T_{2}, T_{4}$ OC \\
8 & $T_{1}, T_{2}, T_{3}, T_{4}$ OC \\
9 & $T_{1}, T_{2}, T_{3}, T_{4}, T_{5}$ OC \\
10 & $T_{1}, T_{2}, T_{3}, T_{4}, T_{5}, T_{6}$ OC \\
\hline
\end{tabular}

fault switching devices are triggered to simulate the system's different fault degree. And the switch's open circuit faults are simulated through the blockade of the pulses by dSPACE software. Table 1 is the system health degradation state table.
Figure 6 is induction motor simulation model which is controlled by the rotor field-oriented vector. The step length of simulation model is fixed in discrete simulation algorithm. The simulation step size is usually chosen as one percent of the switching cycle. In this simulation the switching frequency is $5 \mathrm{kHZ}$ and the simulation step $T_{s}$ is $2 e-6 \mathrm{~s}$.

As shown in Figure 7, the simulation model includes seven modules, of which the main circuit is a typical LCI structure, including a three-phase diode rectifier, DC filter unit, three-phase inverter, measuring unit, and the motor model. Three-phase $380 \mathrm{~V} / 50 \mathrm{~Hz}$ AC power runs through a rectifier and a DC link filter and then from the three-phase AC voltage inverter to the induction motor. The speed control system includes a speed control module and a field-oriented control module.

5.2. Health Degradation Simulation and Calculation. Figure 8 is the motor drive system's fault simulation test platform. $\mathrm{DC}$ voltage is about $513 \sim 537 \mathrm{~V}$ which is rectified from $380 \mathrm{~V}$ 
TABLE 2: Degradation data tables of system health state.

\begin{tabular}{lccccccccc}
\hline Number & Condition & $x_{1}$ & $x_{2}$ & $x_{3}$ & $x_{4}$ & $x_{5}$ & $x_{6}$ & $x_{7}$ & $x_{8}$ \\
\hline 1 & Healthy & 0.05 & 0.03 & 0.02 & 0.03 & 0.04 & 0.02 & 0.01 & 0.02 \\
2 & $T_{1}$ OC & 0.11 & 0.1 & 0.13 & 0.09 & 0.16 & 0.08 & 0.15 & 0.1 \\
3 & $T_{1}, T_{2}$ OC & 0.23 & 0.2 & 0.19 & 0.16 & 0.18 & 0.24 & 0.22 & 0.17 \\
4 & $T_{1}, T_{2}, T_{3}$ OC & 0.26 & 0.33 & 0.28 & 0.32 & 0.31 & 0.34 & 0.33 & 0.35 \\
5 & $T_{1}, T_{2}, T_{3}, T_{4}$ OC & 0.41 & 0.45 & 0.38 & 0.42 & 0.46 & 0.47 & 0.42 & 0.4 \\
6 & $T_{1}, T_{2}, T_{3}, T_{4}, T_{5}$ OC & 0.71 & 0.75 & 0.68 & 0.72 & 0.66 & 0.57 & 0.72 & 0.74 \\
7 & $T_{1}, T_{2}, T_{3}, T_{4}, T_{5}, T_{6}$ OC & 0.81 & 0.85 & 0.78 & 0.82 & 0.86 & 0.77 & 0.82 & 0.84 \\
\hline
\end{tabular}

TABLE 3: System health assessment results.

\begin{tabular}{lccc}
\hline Number & Condition & Fault degree & Health degree \\
\hline 1 & Healthy & 0.1 & $90 \%$ \\
2 & $T_{1}$ OC & 0.2 & $80 \%$ \\
4 & $T_{1}, T_{2}$ OC & 0.4 & $60 \%$ \\
6 & $T_{1}, T_{2}, T_{3}$ OC & 0.5 & $50 \%$ \\
8 & $T_{1}, T_{2}, T_{3}, T_{4}$ OC & 0.6 & $40 \%$ \\
9 & $T_{1}, T_{2}, T_{3}, T_{4}, T_{5}$ OC & 0.7 & $30 \%$ \\
10 & $T_{1}, T_{2}, T_{3}, T_{4}, T_{5}, T_{6}$ OC & 0.9 & $10 \%$ \\
\hline
\end{tabular}

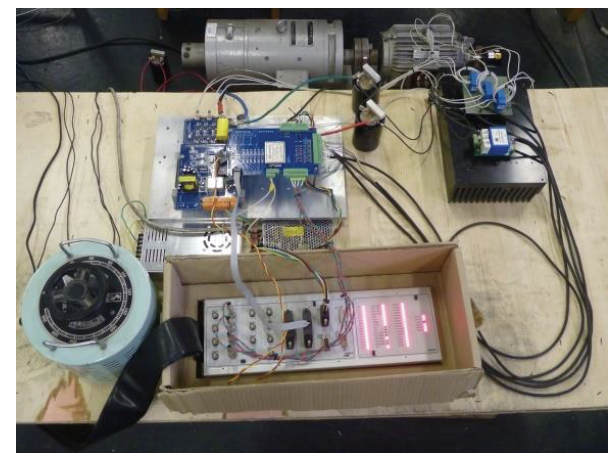

FIGURE 8: Motor drive system fault simulation test platform.

three-phase AC voltage by the uncontrollable rectifier. Then the DC voltage is transformed to three-phase AC by the IPM module, and the inverter output power is $2.2 \mathrm{~kW}$ of the induction motor load. From the dSPACE simulation platform we can get eight state variables. And they can be acquired and preprocessed as the health degrees as in Table 2.

Different switching devices faults are triggered to simulate different fault degrees of motor drive system. The health degraded data in Table 2 is input into the self-organizing feature map network with MATLAB2011b. The network's connection weights, weight distance, and position are shown in Figures 9 11, and the health assessment results are in Table 3. From the table, we can see that, with the increase of the number of fault switching devices, the system fault degree increased, and the health degree reduced. What is more, when the number of faults is one, the health degree is still 80 percent, which means the system can still operate in a degraded state. When the number of faults is two, the health degree is 60 percent which drops 20 percent compared with

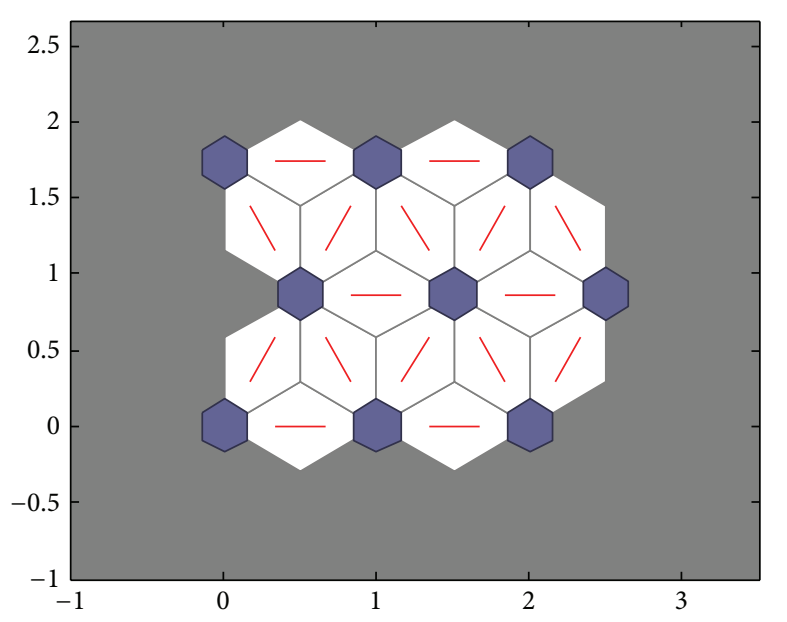

FIGURE 9: SOM neighbor connections.

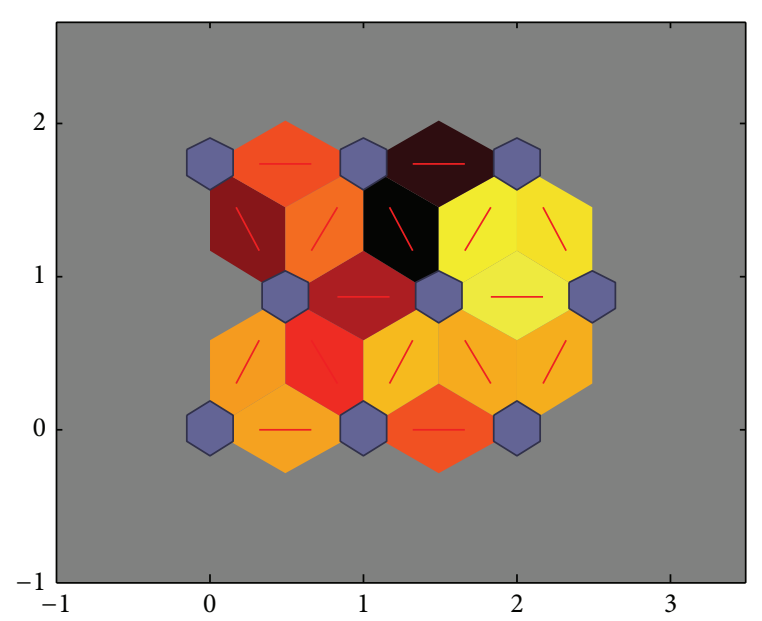

FIgURE 10: SOM neighbor weight distances.

one fault device. But it is still above 50 percent which is higher than three or more fault devices. So we must take tolerance control measures or maintenance action to keep the system safe before two fault devices as soon as possible in order to avoid property loss or casualties. 


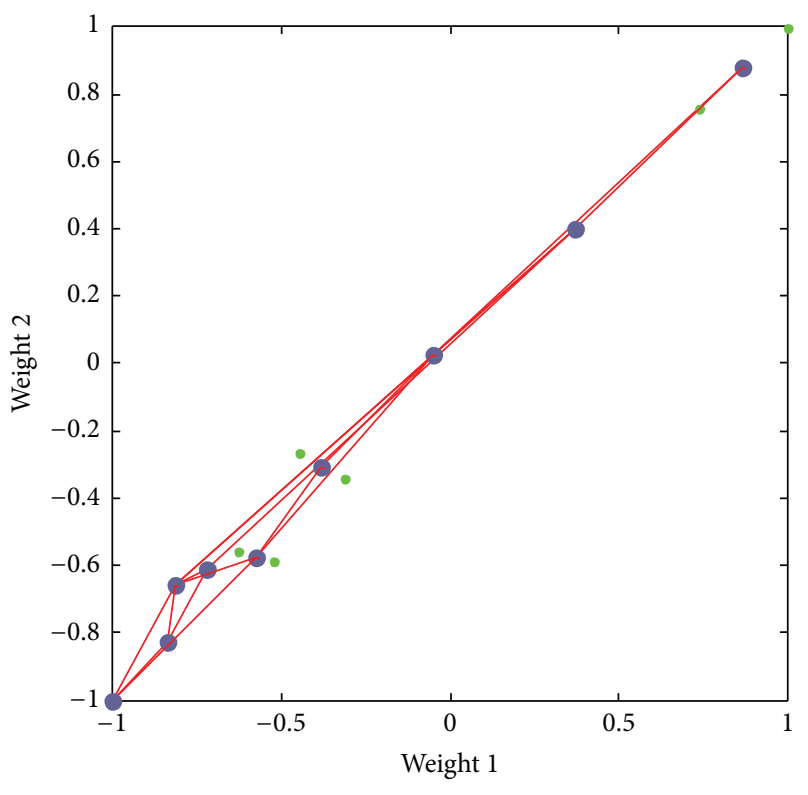

FIGURE 11: SOM weight positions.

\section{Conclusions}

This paper extracted the health variables of the motor drive system by analyzing the control principles and fault mechanism firstly. Then they are preprocessed to get the health degree. With the self-organizing feature map network's unsupervised and autonomous learning characteristics, the system fault is clustered and recognized quickly through the competition clustering. The fault of the switching device is taken as example to validate the algorithm by the simulation experiment and demonstration. Finally the health degree is put forward to complete the system's health assessment, which has an important guiding significance for railway motor drive system's safety assessment and maintenance.

Of course, due to the limited time and ability, this paper just put forward a preliminary health assessment scheme and algorithm. Later there is a need for research of the capacitance's aging damage, electrical insulation failure, sensor failure, and also the analysis of different failure mode effect on the system in order to realize the online health assessment and safety early warning for the train's safety, reliability, and stability.

\section{Competing Interests}

The authors declare that they have no competing interests.

\section{Acknowledgments}

The work was supported by the National Natural Science Foundation of High Speed Rail Joint Funds (U1134204).

\section{References}

[1] Y. Lu Murphey, M. Abul Masrur, Z.-H. Chen, and B. Zhang, "Model-based fault diagnosis in electric drives using machine learning," IEEE/ASME Transactions on Mechatronics, vol. 11, no. 3, pp. 290-303, 2006.

[2] H.-B. Cheng, Z.-Y. He, H.-T. Hu, X.-Q. Mu, B. Wang, and Y.$\mathrm{X}$. Sun, "Comprehensive evaluation of health status of highspeed railway catenaries based on entropy weight," Journal of the China Railway Society, vol. 36, no. 3, pp. 19-24, 2014.

[3] P. Zhi-Song, W. Qiong, N. Gui-Qiang, and H. Gu-Yu, "A SOM-based of fault diagnosis for WAN," in Proceedings of the International Conference on Industrial and Information Systems (IIS '09), pp. 207-210, Haikou, China, April 2009.

[4] M. Shi, C. Zhao, and Z. Guo, "Forest health assessment based on self-organizing map neural network," Chinese Journal of Ecology, vol. 30, no. 6, pp. 1295-1303, 2011.

[5] L.-H. Meng, Z.-G. Liu, L.-J. Diao, C.-M. Xu, and L. Wang, "Evaluation of reliability of urban rail train traction inverter system," Journal of the China Railway Society, vol. 36, no. 9, pp. 34-38, 2014.

[6] H. Wang, Y. Wang, and C. Xie, "Reliability modeling and assigning for CRH2 electric multiple unit," Journal of the China Railway Society, vol. 31, no. 5, pp. 108-112, 2009.

[7] X. Lu, Z. Liu, and M. Shen, "Research on the damage model of electrical locomotives traction subsystem based on the stress damage," Journal of Beijing Jiaotong University, vol. 33, no. 6, pp. 13-16, 2009.

[8] M. Molaei, H. Oraee, and M. Fotuhi-Firuzabad, "Markov model of drive-motor systems for reliability calculation," in Proceedings of the International Symposium on Industrial Electronics (ISIE '06), pp. 2286-2291, Québec, Canada, July 2006.

[9] J.-S. Wang, S.-X. Li, and J. Gao, "SOM neural network fault diagnosis method of polymerization kettle equipment optimized by improved PSO algorithm," The Scientific World Journal, vol. 2014, Article ID 937680, 12 pages, 2014.

[10] B. Akin, S. Choi, U. Orguner, and H. A. Toliyat, "A simple realtime fault signature monitoring tool for motor-drive-embedded fault diagnosis systems," IEEE Transactions on Industrial Electronics, vol. 58, no. 5, pp. 1990-2001, 2011.

[11] J. M. Bossio, C. H. De Angelo, G. R. Bossio, and G. O. García, "Fault diagnosis on induction motors using Self-Organizing Maps," in Proceedings of the 9th IEEE/IAS International Conference on Industry Applications (INDUSCON '10), pp. 1-6, Sao Paulo, Brazil, November 2010.

[12] R. L. De Araujo Ribeiro, C. B. Jacobina, E. R. C. Da Silva, and A. M. N. Lima, "Fault detection of open-switch damage in voltagefed PWM motor drive systems," IEEE Transactions on Power Electronics, vol. 18, no. 2, pp. 587-593, 2003.

[13] F. Filippetti, G. Franceschini, C. Tassoni, and P. Vas, "Recent developments of induction motor drives fault diagnosis using AI techniques," IEEE Transactions on Power Electronics, vol. 47, no. 5, pp. 994-1004, 2002.

[14] S. Khomfoi and L. M. Tolbert, "Fault diagnosis and reconfiguration for multilevel inverter drive using AI-based techniques," IEEE Transactions on Industrial Electronics, vol. 54, no. 6, pp. 2954-2968, 2007.

[15] Y. L. Murphey, M. A. Masrur, Z. Chen, and B. Zhang, "Modelbased fault diagnosis in electric drives using machine learning," IEEE/ASME Transactions on Mechatronics, vol. 11, no. 3, pp. 290-303, 2006. 
[16] J. O. Estima and A. J. M. Cardoso, "A new approach for realtime multiple open-circuit fault diagnosis in voltage-source inverters," IEEE Transactions on Industry Applications, vol. 47, no. 6, pp. 2487-2494, 2011.

[17] C. U. Bowen, "Simulation study for inverter-fed motor drive system under fault conditions," Electric Machines and Control, vol. 11, no. 6, pp. 578-583, 2007.

[18] D. Diallo, M. E. H. Benbouzid, D. Hamad, and X. Pierre, "Fault detection and diagnosis in an induction machine drive: a pattern recognition approach based on concordia stator mean current vector," IEEE Transactions on Energy Conversion, vol. 20, no. 3, pp. 512-519, 2005.

[19] C. Delpha, D. Diallo, E. H. B. Mohamed, and C. Marchand, "Pattern recognition for diagnosis of inverter FED induction machine drive: a step toward reliability," in Proceedings of the IET Colloquium on Reliability of Electromagnetic Systems, pp. 15, Paris, France, May 2007. 


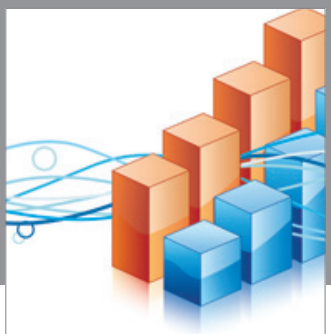

Advances in

Operations Research

vatem alat4

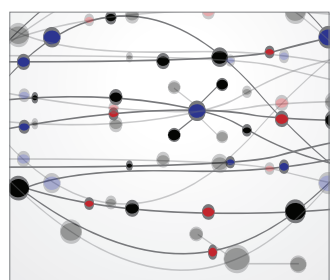

\section{The Scientific} World Journal
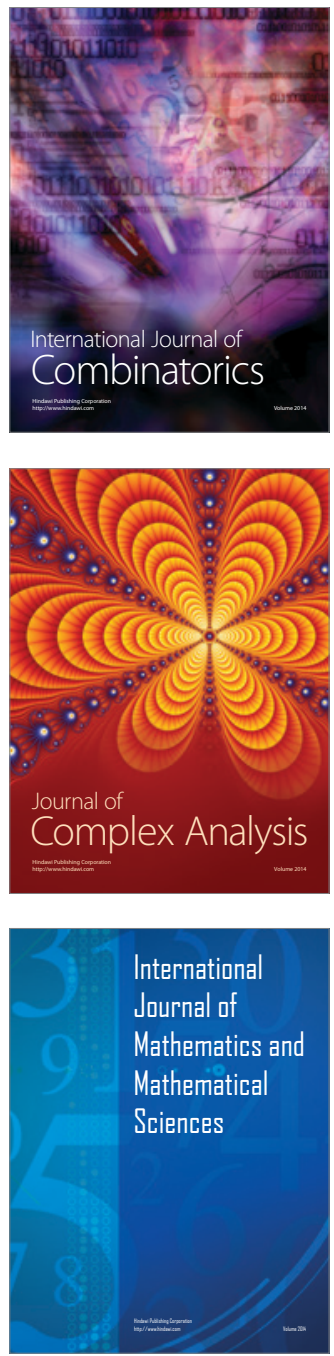
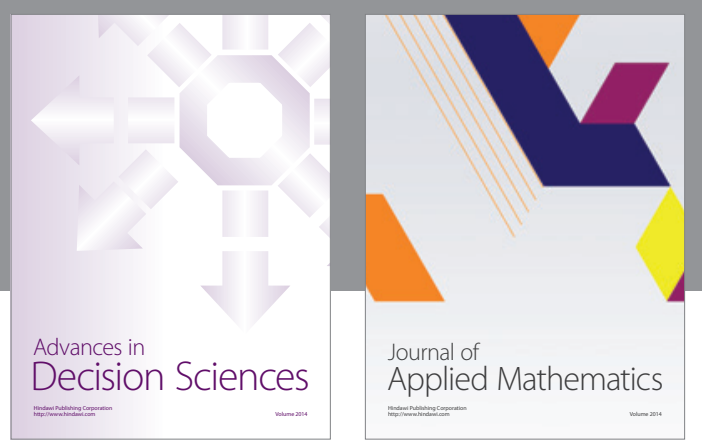

Algebra

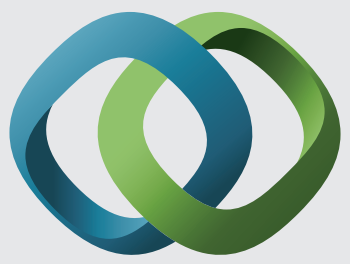

\section{Hindawi}

Submit your manuscripts at

http://www.hindawi.com
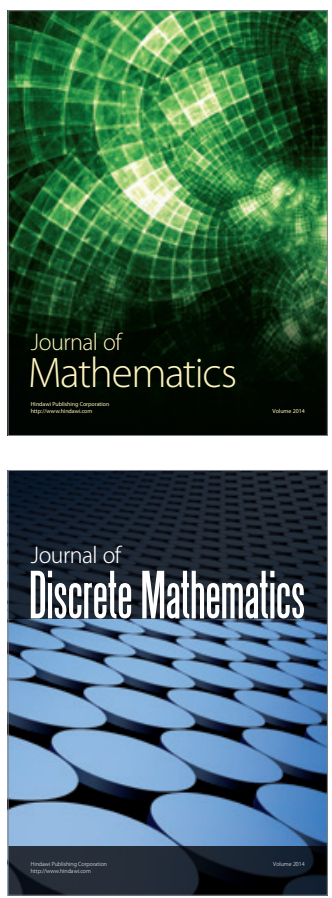

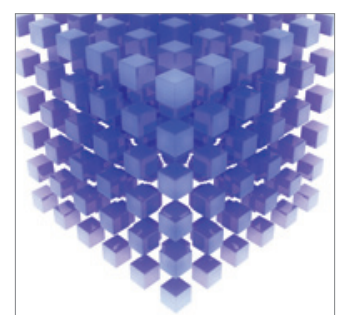

Mathematical Problems in Engineering
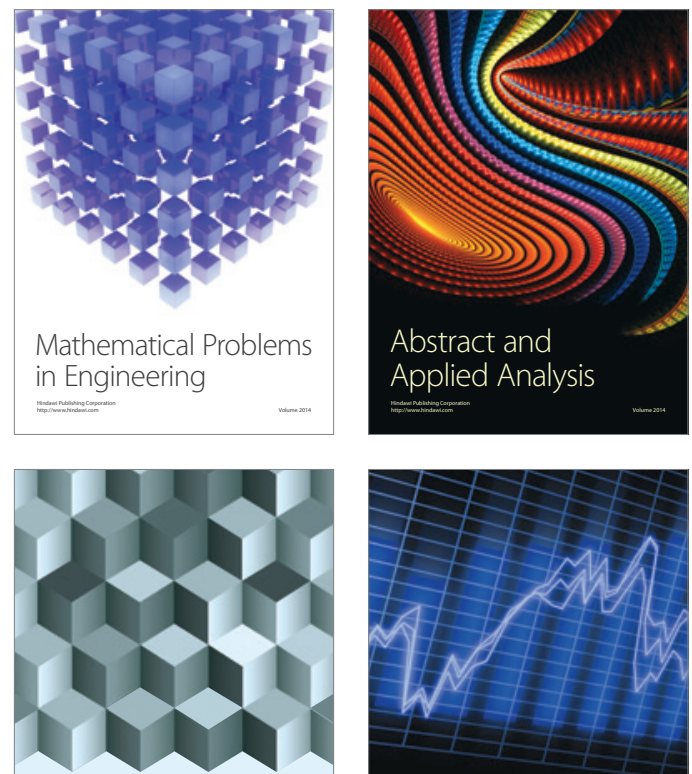

Journal of

Function Spaces

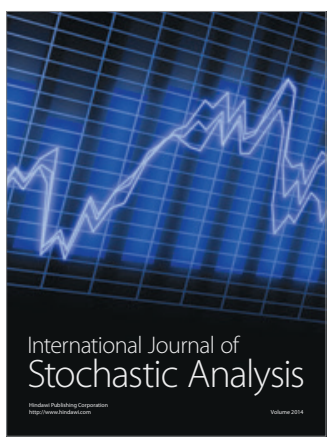

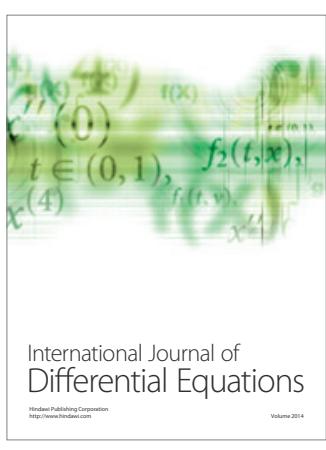
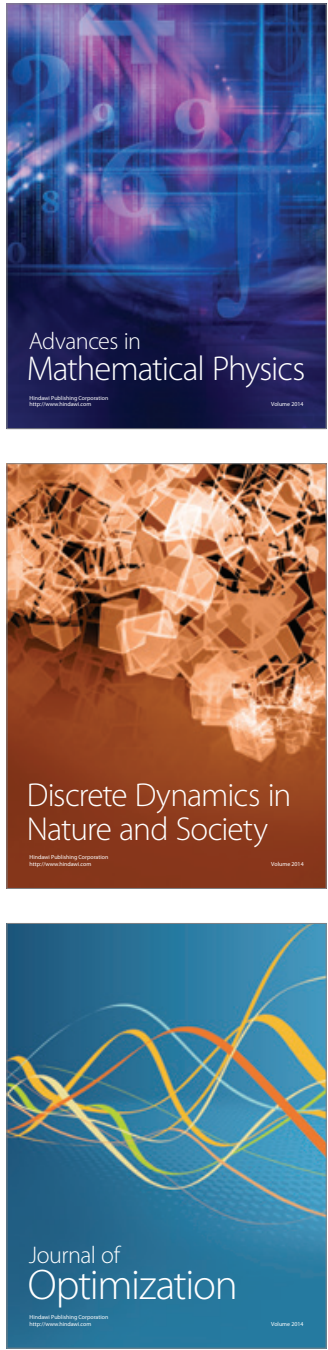